\title{
Pengaruh Debt to Asset Ratio dan Debt to Equity Ratio terhadap Return on Equity pada Perusahaan Properti dan Real Estate
}

\author{
The effects of debt to asset ratio and debt to equity to return on equity on property and real estate \\ companies
}

\section{Yunita Rizka Septiyani}

Program Studi D3 Keuangan dan Perbankan, Politeknik Negeri Bandung

Email: yunita.rizka.kepn17@polban.ac.id

\section{Kristianingsih}

Jurusan Akuntansi, Politeknik Negeri Bandung

E-mail: kristianingsih@polban.ac.id

\section{Muhamad Umar Mai}

Jurusan Akuntansi, Politeknik Negeri Bandung

E-mail: umar.mai@polban.ac.id

\begin{abstract}
The purpose of this research is to determine the Effect of Debt to Asset Ratio (DAR) and Debt to Equity Ratio (DER) to Return On Equity (ROE) of property and real estate companies listed in IDX for 2013-2017 both simultaneously and partially. The used research methods are descriptive and quantitative approaches, with secondary data using IBM SPSS Statistics 23 application tool. There are 40 sample data choosen by purposive sampling. Based on the results of the F test simultaneously Debt to Asset Ratio (DAR) and Debt to Equity Ratio (DER) have a significant effect on Return On Equity (ROE). Based on bypothetical testing, the t test bring the result that debt to asset ratio (DAR) has an insignificant effect on return on equity (ROE) variables and Debt to Equity Ratio (DER) has a significant effect on Return on Equity (ROE) variables on property and real estate companies listed in IDX.
\end{abstract}

Keywords: debt to asset ratio, debt to equity ratio, return on equity

\section{Pendahuluan}

Dalam dunia bisnis mengalami persaingan yang semakin kuat. Tentu menjadikan para manajer harus meningkatkan profitabilitas perusahaan (Mai dan Setiawan, 2020). Salah satu sektor yang menjadi perhatian yaitu bidang properti dan real estate. Hal ini menjadi salah satu tolak ukur untuk melihat seberapa baik kesehatan ekonomi pada suatu negara. Menurut Santoso (2005) sebuah industri properti dan real estate yaitu salah satu bagian yang memberi tanda jatuh atau sedang dalam pembangunan pada perekonomian suatu negara. Hal ini memiliki makna bahwa akan terjadi perkembangan di Indonesia dan diprediksi semakin banyak industri yang mulai fokus dan tertarik dibidang sektor properti dan real estate.

Bersumber data Badan Pusat Statistik (BPS) menyebutkan bahwa di Indonesia yang memiliki status kepemilikan rumah kontrak atau sewa pada tahun 2013 hingga 2017 mengalami kenaikan namun masih sangat kecil persentasenya yaitu 8,06\% menjadi 9,64\%. Sehingga bisnis properti dan real estate sangat berpeluang besar untuk para pengusaha menanamkan modal.

Dalam hal ini para manajer harus terus menambah tingkat laba agar perusahaannya dapat 
berkembang. Anggaran yang dibutuhkan dalam mengembangkan suatu perusahaan tentu tidak sedikit agar keuntungan yang didapatkan maksimal. Kebutuhan anggaran yang terus bertambah seiring dengan besarnya aktivitas yang dilakukan suatu perusahaan, membutuhkan dana yang lebih besar baik bersumber dari internal maupun eksternal perusahaan. Namun, target dari perusahaan adalah untuk memperoleh kemakmuran dan keuntungan bagi para pemegang sahamnya.

Profitabilitas adalah alat ukur untuk melihat kemampuan perusahaan dalam menghasilkan laba. Penggunaan utang pada tingkat bunga tertentu akan memiliki pengaruh yang cukup besar terhadap ROE karena semakin tinggi tingkat bunga utang, maka akan semakin tinggi beban tetap terhadap pendapatan sehingga kondisi tersebut kurang baik terhadap ROE dan begitu juga sebaliknya. Bentuk investasi sebagai tambahan untuk mendanai asset perusahaan dengan tujuan memperoleh laba yaitu penggunaan utang. Variabel Debt to Asset Ratio (DAR) dan Debt to Equity Ratio (DER) mewakilkan untuk melihat berapa besar pinjaman yang dibutuhkan dari pihak luar.

Rasio solvabilitas membantu perusahaan dalam memenuhi kewajiban utang jangka panjang. Apabila rasio ini terlihat tinggi nilainya berarti modal perusahaan terlihat besar dan peluang untuk mendapatkan keuntungan semakin besar pula. Sedangkan profitabilitas menginginkan agar sebagian besar dana yang diperoleh perusahaan dari pihak luar baik berupa pinjaman maupun investasi dari investor bisa dioperasikan agar dapat memperoleh hasil yang lebih tinggi.

Berdasarkan data yang telah diolah maka rasio solvabilitas dan profitabilitas pada periode 2013-2017 pada subsektor properti dan real estate dapat dilihat

Tabel 1.1 Perkembangan DAR, DER dan ROE periode 2013-2017

\begin{tabular}{|l|l|l|l|}
\hline \multirow{2}{*}{ TAHUN } & \multicolumn{3}{|c|}{ Variabel } \\
\cline { 2 - 4 } & DAR & DER & ROE \\
\hline 2013 & $42,51 \%$ & $73,94 \%$ & $10,50 \%$ \\
\hline 2014 & $42,28 \%$ & $73,24 \%$ & $10,64 \%$ \\
\hline 2015 & $43,87 \%$ & $78,17 \%$ & $8,71 \%$ \\
\hline 2016 & $42,39 \%$ & $73,59 \%$ & $8,26 \%$ \\
\hline 2017 & $42,11 \%$ & $72,73 \%$ & $5,40 \%$ \\
\hline
\end{tabular}

Sumber : Hasil olah data

Rata-rata dari variabel DAR dalam tabel diatas mengalami penurunan begitu juga dengan DER pada periode 2013 dan 2014 masing-masing sebesar 0,23\% dan 0,7\%, sedangkan ROE mengalami kenaikan sebesar $0,14 \%$. Terlihat hubungan yang berbeda arah antara rasio solvabilitas dan profitabilitas yaitu peningkatan profitabilitas, namun terjadi penurunan terhadap rasio solvabilitas. Variabel DAR maupun DER masing-masing dalam penelitian ini untuk menjelaskan pengaruh atau tidak dan seberapa besar taraf signifikansi pengaruh terhadap variabel ROE secara simultan dan untuk menjelaskan pengaruh DAR dan DER secara parsial berpengaruh atau tidak terhadap ROE pada perusahaan properti dan real estate periode 2013-2017.

\section{Kajian Pustaka}

\subsection{Debt to Asset Ratio (DAR)}

Pengertian Debt to Asset Ratio (DAR) yang dikemukakan oleh Kasmir (2014:196) Rasio yang dipergunakan sebagai parameter antara jumlah utang dengan jumlah aset. Dalam arti, melihat 
tingkat tingginya aset setiap perusahaan yang dibiayai oleh utang atau melihat tinggi dan pengaruh utang perusahaan terhadap cara mengendalikan aset. Maka semakin besar tingkat rasio, semakin besar pula modal pinjaman yang dipergunakan untuk investasi pada aset dalam memperoleh laba bagi perusahaan (Prakarsa dan Setiawan, 2018).

\subsection{Debt to Equity Ratio (DER)}

Kasmir (2014:157) berpendapat bawah Debt to Equity Ratio (DER) yaitu alat ukur untuk mengetahui besaran utang dengan ekuitas. Variabel DER mampu menjelaskan tingkat perbandingan dari ekuitas perusahaan yang bersumber dari eksternal.

\subsection{Return On Equity (ROE)}

Pengertian rasio Return on Equity (ROE) menurut Sartono (2012:124) menyatakan bawah suatu alat ukur untuk melihat tingkat kemampuan setiap perusahaan dalam memperoleh keuntungan yang nantinya akan dibagikan kepada para investor perusahaan. Dalam hal ini, besar atau kecil rasio ROE mendapat pengaruh dari utang perusahaan, apabila perbandingan utang semakin tinggi maka rasio ini juga semakin tinggi.

\subsection{Kerangka Pemikiran}

Perusahaan properti dan real esatete memakai anggaran biaya dalam proses hal pengembangan perusahaan dengan tujuan memperoleh laba. Laporan keuangan perusahaan yang digunakan untuk melihat seberapa besar biaya dari masing-masing perusahaan. Dalam memudahkan penjelasan kerangka pemikiran dibuat bagan sebagai berikut:

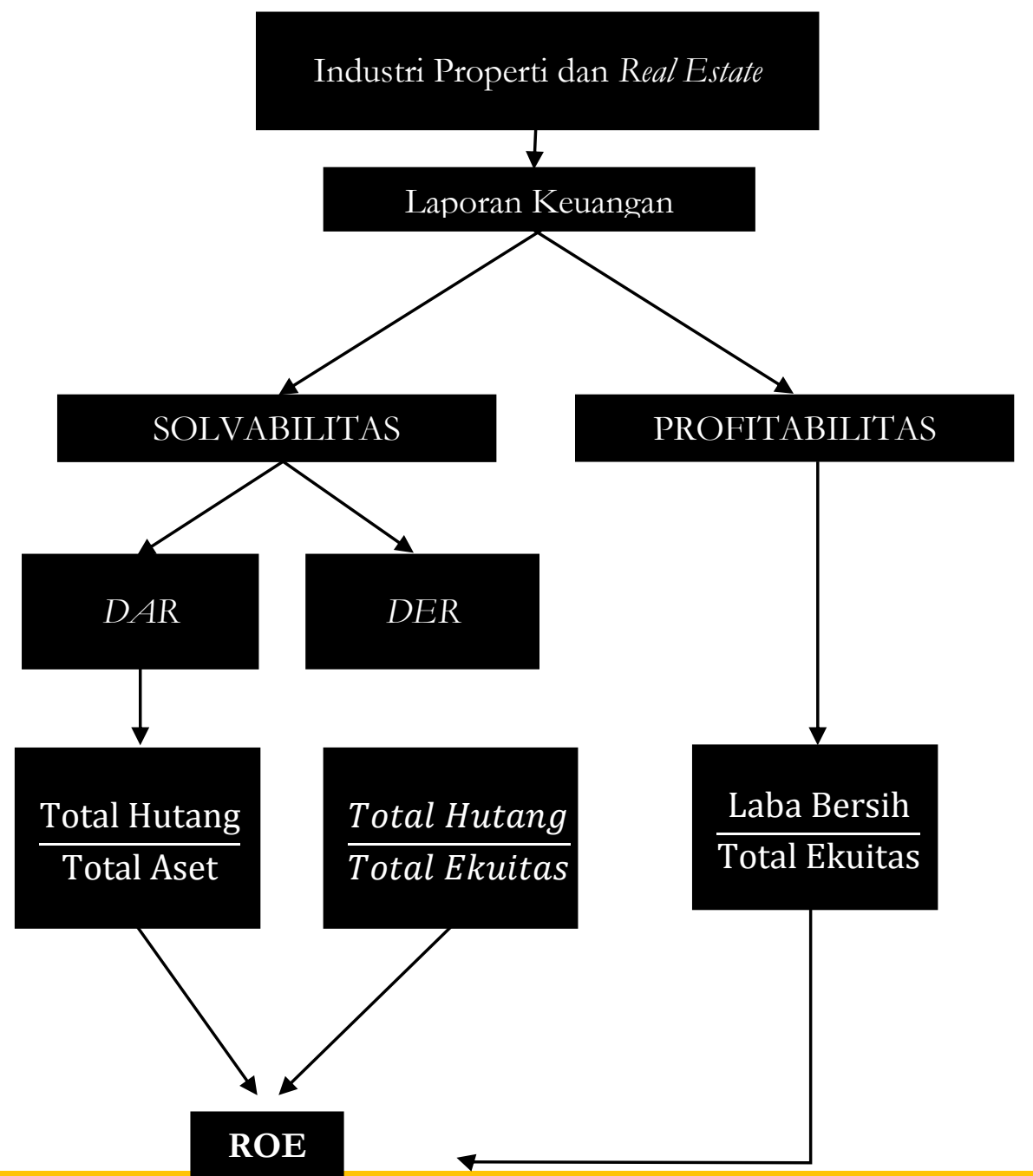




\section{Metode Penelitian}

Metode yang digunakan peneliti yaitu metode deskriptif dan metode kuantitatif karena untuk memperoleh penjelasan yang lebih luas terhadap fenomena yang telah ditetapkan sebagai objek penelitian (Rully, 2016:29). Jumlah populasi yang tercatat sebanyak 60 perusahaan. Kriteria tertentu dalam hal menentukan sampel, diantaranya tercatat di BEI mapupun situs web resmi perusahaan dengan periode yang diteliti 2013-2017 pada subsektor properti dan real estate dan memiliki data yang lengkap.

Tabel 3.1 Sampel Penelitian

\begin{tabular}{|c|c|l|}
\hline No & $\begin{array}{c}\text { Kode } \\
\text { Perusahaan }\end{array}$ & \multicolumn{1}{|c|}{ Nama Perusahaan } \\
\hline 1 & BAPA & PT Bekasi Asri Pemula Tbk \\
\hline 2 & BKSL & PT Sentul City Tbk \\
\hline 3 & CTRA & PT Ciputra Development Tbk \\
\hline 4 & DART & PT Duta Anggada Realty Tbk \\
\hline 5 & DUTI & PT Duta Pertiwi Tbk \\
\hline 6 & GMTD & PT Goa Makassar Tourism Development Tbk \\
\hline 7 & GPRA & PT Perdana Gapura Prima Tbk \\
\hline 8 & KIJA & PT Kawasan Industri Jababeka Tbk \\
\hline
\end{tabular}

Sumber : Hasil olah data dari sahamok.com

\subsection{Variabel Operasional}

Tabel 3.2 Variabel Operasional

\begin{tabular}{|c|c|c|c|}
\hline Variabel & Konsep Variabel & Indikator & Satuan \\
\hline DAR & $\begin{array}{l}\text { Rasio untuk melihat } \\
\text { seberapa mampu aset } \\
\text { yang dibiayai utang pada } \\
\text { suatu perusahaan. }\end{array}$ & $\mathrm{DAR}=\frac{\text { Total Asset }}{\text { Total Asset }}$ & Rasio \\
\hline DER & $\begin{array}{lr}\text { Rasio untuk mengukur } \\
\text { ketersediaan } & \text { dana } \\
\text { kreditor } & \text { untuk } \\
\text { dipinjamkan } & \text { kepada } \\
\text { pemilik perusahaan. }\end{array}$ & $\mathrm{DER}=\frac{\text { Total Debt }}{\text { Ekuitas }}$ & Rasio \\
\hline $\mathrm{ROE}$ & $\begin{array}{lr}\text { Rasio } & \text { untuk melihat } \\
\text { tingkat } & \text { kemampuan }\end{array}$ & ROE $=\frac{\text { Laba Bersih Setelah Pajak }}{\text { Total Ekuitas }}$ & Rasio \\
\hline
\end{tabular}




\begin{tabular}{|l|l|l|l|}
\hline setiap perusahaan dalam & & \\
memperoleh keuntungan & & & \\
yang nantinya akan & & & \\
dibagikan kepada para & & \\
investor perusahaan. & & \\
\hline
\end{tabular}

\subsection{Rancangan Analisis}

Dalam pengolahan data dibantu dengan Microsoft Office Excel 2013 dan program aplikasi SPSS versi 25 untuk melihat pengaruh variabel bebas DAR (X1), DER (X2) terhadap variabel terikat tak lain $\mathrm{ROE}(\mathrm{Y})$. Berikut model persamaan regresi:

$$
Y=a+b 1 x 1+b 2 X 2
$$

Keterangan:

$\mathrm{Y}=$ Variabel terikat

a $=$ Constant

$\mathrm{b} \quad=$ Regression-Coefficient

$\mathrm{X} 1=$ variabel bebas

$\mathrm{X} 2=$ variabel bebas

\section{Hasil dan Pembahasan}

\subsection{Statistik Deskriptif}

Tabel 4.1 Output Statistik Deskriptif Variabel-variabel Penelitian

\begin{tabular}{|c|c|c|c|c|c|}
\multicolumn{7}{c}{ Descriptive Statistics } \\
& N & Minimum & Maximum & Mean & Std. Deviation \\
\hline ROE & 40 & .01 & .23 & .0857 & .05376 \\
\hline DAR & 40 & .19 & .69 & .4127 & .10650 \\
\hline DER & 40 & .24 & 2.24 & .7626 & .35874 \\
\hline Valid N (listwise) & 40 & & & & \\
\hline
\end{tabular}

a. Test distribution is Normal.

b. Calculated from data.

c. Lilliefors Significance Correction.

d. This is a lower bound of the true significance.

Sumber: Output IBM SPSS 25

Pada tabel diatas menunjukkan ROE terdapat nilai minimum sebesar- 0,01, nilai maximum sebesar 0,23 dan nilai mean sebesar 0,0857. Lalu DAR menunjukkan nilai minimum sebesar 0,19, nilai maximum sebesar 0,69, dan untuk nilai mean sebesar 0,4127. Adapun variabel DER menunjukkan nilai minimum sebesar 0,24, nilai maximum sebesar 2,24 dan nilai mean sebesar 0,7626. 


\subsection{Uji Analisis Statistik}

\section{Uji Normalitas}

Tabel 4.2 Output One-Sample Kolmogorov-Smimov Test

One-Sample Kolmogorov-Smirnov Test

\begin{tabular}{llr} 
& & $\begin{array}{c}\text { Unstandardized } \\
\text { Residual }\end{array}$ \\
\hline $\mathrm{N}$ & Mean & 40 \\
\cline { 2 - 3 } Normal Parameters,b, & Std. Deviation & .00000000 \\
\hline Most Extreme Differences & Absolute & .073 \\
\cline { 2 - 3 } & Positive & .073 \\
\cline { 2 - 3 } & Negative & -.059 \\
\hline Test Statistic & & .073 \\
\hline Asymp. Sig. (2-tailed) & & $.200 \mathrm{c}, \mathrm{d}$ \\
\hline
\end{tabular}

a. Test distribution is Normal.

b. Calculated from data.

c. Lilliefors Significance Correction.

d. This is a lower bound of the true significance.

Sumber: Output IBM SPSS 25

Dari tabel yang menunjukkan hasil dari uji kolmogrov-smirnov pada nilai residual sebesar 0,200 lebih besar dari nilai signifikansi sebesar 0,05. Sesuai dengan data diatas menunjukkan memenuhi uji normalitas dan data berdistribusi normal.

\section{Uji Multikolinearitas}

Tabel 4.3 Output Uji Multikolinearitas

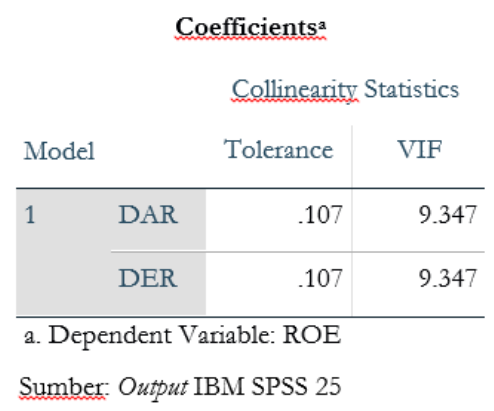


Hasil dari tabel diatas dapat dilihat nilai tolerance dan VIF dari dua variabel bebas yaitu DAR dan DER sebesar 0,107 dan 9,347. Dari hasil yang diperoleh, maka dapat dinyatakan bahwa nilai tolerance $>0,1$ dan nilai VIF $<10$, sehingga dapat dikatakan tidak terjadi mulikolinearitas.

\section{Uji Heteroskedastisitas}

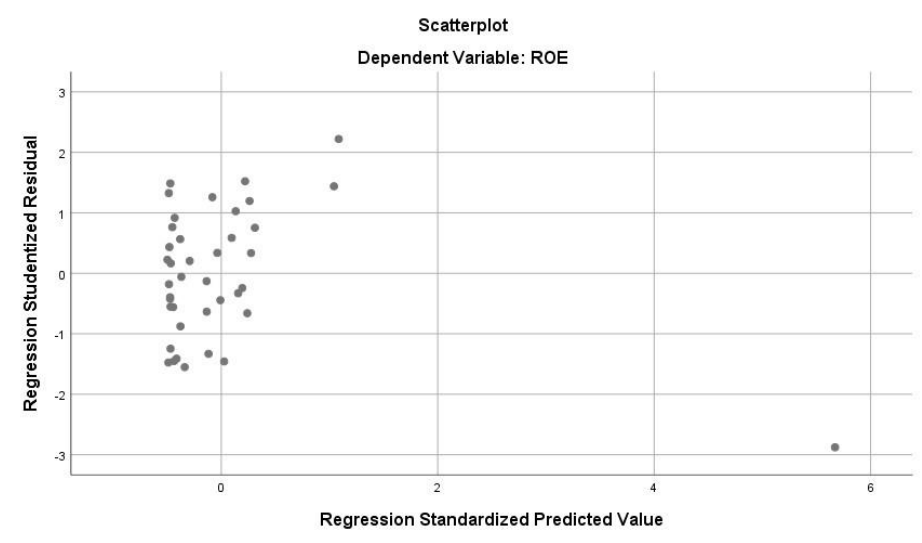

Gambar 4.1 Gambar Grafik Scatterplot

Pada gambar Scatterplot diatas menyatakan bahwa tidak terdapat heteroskedastisitas karena tidak membentuk pola tertentu dan menyebar secara acak titik-titiknya, baik diatas maupun dibawah angka 0 pada sumbu $Y$.

Tabel 4.4 Output Uji Glesjer

Coefficientsa

\begin{tabular}{|c|c|c|c|c|c|c|}
\hline \multicolumn{7}{|c|}{ Coefficients } \\
\hline \multirow[b]{2}{*}{ Model } & & \multicolumn{2}{|c|}{ Unstandardized Coefficients } & \multirow{2}{*}{$\begin{array}{c}\text { Standardized } \\
\text { Coefficients } \\
\text { Beta }\end{array}$} & \multirow[b]{2}{*}{$\mathrm{T}$} & \multirow[b]{2}{*}{ Sig. } \\
\hline & & B & Std. Error & & & \\
\hline \multirow[t]{3}{*}{1} & (Constant) & .002 & .021 & & .110 & .913 \\
\hline & DAR & .075 & .098 & .355 & .765 & .449 \\
\hline & DER & .002 & .029 & .033 & .072 & .943 \\
\hline
\end{tabular}

a. Dependent Variable: ABRESID

Sumber: Output IBM SPSS 25

Berdasarkan Uji Glejser diatas didapatkan nilai signifikansi DAR sebesar 0,449 dan nilai signifikansi DER sebesar 0,943. Hal ini menunjukkan nilai signifikansi kedua variabel lebih besar dari 0,05, sehingga penelitian ini dapat digunakan karena tidak terjadi heteroskedastisitas.

\section{Uji Autokorelasi}




\section{Tabel 4.5 Output Durbin-Watson}

\begin{tabular}{|c|c|c|c|c|c|}
\hline \multicolumn{6}{|c|}{ Model Summary } \\
\hline Model & $\mathrm{R}$ & R Square & $\begin{array}{l}\text { Adjusted R } \\
\text { Square }\end{array}$ & $\begin{array}{l}\text { Std. Error of } \\
\text { the Estimate }\end{array}$ & $\begin{array}{l}\text { Durbin- } \\
\text { Watson }\end{array}$ \\
\hline 1 & $.623^{\mathrm{a}}$ & .389 & .356 & .04316 & 1.216 \\
\hline \multicolumn{6}{|c|}{ a. Predictors: (Constant), DER, DAR } \\
\hline \multicolumn{6}{|c|}{ b. Dependent Variable: ROE } \\
\hline
\end{tabular}

Autokorelasi senilai 1,216 hasil dari uji Durbin-Watson, artinya nila Durbin-Watson tidak ada autokorelasi karena terletak diantar nilai -2 hingga +2 .

\section{Uji Goodsness of Fit (Uji F)}

Tabel 4.6 Output Uji Statistik F

\begin{tabular}{|c|c|c|c|c|c|c|}
\hline \multicolumn{7}{|c|}{ ANOVAa } \\
\hline Model & & Sum of Squares & $\mathrm{Df}$ & Mean Square & $\mathrm{F}$ & Sig. \\
\hline \multirow[t]{3}{*}{1} & Regression & .044 & 2 & .022 & 11.761 & $.000^{\mathrm{b}}$ \\
\hline & Residual & .069 & 37 & .002 & & \\
\hline & Total & .113 & 39 & & & \\
\hline
\end{tabular}

a. Dependent Variable: ROE

b. Predictors: (Constant), DER, DAR

Sumber: Output IBM SPSS 25

Dari hasil perhitungan statistik diketahui nilai signifikansi $0,000<0,05$ (tingkat signifikansi). Sedangkan nilai 3,24 hasil perhitungan F tabel, Karena F tabel $<F$ hitung yaitu 3,24 < 11,761. Berdasarkan hipotesis dapat dikatakan bahwa variabel terikat yaitu ROE dapat dipengaruhi secara signifikan oleh variabel bebas yaitu DAR dan DER.

\section{Uji Korelasi}

Tabel 4.7 Uji Korelasi (R)

\begin{tabular}{|c|c|c|c|c|}
\hline \multicolumn{5}{|c|}{ Model Summary ${ }^{\mathrm{b}}$} \\
\hline Model & $\mathrm{R}$ & R Square & $\begin{array}{l}\text { Adjusted R } \\
\text { Square }\end{array}$ & $\begin{array}{l}\text { Std. Error of } \\
\text { the Estimate }\end{array}$ \\
\hline 1 & $.623^{2}$ & .389 & .356 & .04316 \\
\hline
\end{tabular}

Sumber: Output IBM SPSS 25 
Tabel 4.8 Pedoman untuk memberi interpretasi korelasi

\begin{tabular}{|c|c|}
\hline Interval Koefisien & Tingkat Hubungan \\
\hline $0,00-0,199$ & Sangat rendah \\
\hline $0,20-0,399$ & Rendah \\
\hline $0,40-0,599$ & Sedang \\
\hline $0,60-0,799$ & Kuat \\
\hline $0,80-1,000$ & Sangat kuat \\
\hline
\end{tabular}

Sumber: Sugiyono (2015)

Dari hasil Uji Korelasi diperoleh R sebesar 0,629, berdasarkan hasil yang diperoleh dapat dikatakan memiliki hubungan yang rendaah antara DAR dan DER dengan ROE pada perusahaan properti dan real estate tahun 2013-2017.

\section{Analisis Koefisien Determinasi}

Berdasarkan hasil regresi yang diperoleh dari tabel diatas maka $\mathrm{R}$ square sebesar 0,389. Maka menunjukkan 38,9\% variabel dependen (ROE) dipengaruhi kedua variabel independen yaitu DAR dan DER dan selisihnya sebesar 61,1\% dipengaruhi variabel yang tidak diteliti.

\section{Analisis Regresi Linear Berganda}

Berikut interpretasi yang dilakukan menghasilkan persamaan regresi liniear berganda

Tabel 4.8 Output Analisis Regresi Liniear Berganda

\section{Coefficients $^{\mathrm{a}}$}

\begin{tabular}{|c|c|c|c|c|c|c|}
\hline \multirow{2}{*}{\multicolumn{2}{|c|}{ Model }} & \multicolumn{2}{|c|}{$\begin{array}{l}\text { Unstandardized } \\
\text { Coefficients }\end{array}$} & \multirow{2}{*}{$\begin{array}{c}\text { Standardized } \\
\text { Coefficients } \\
\text { Beta }\end{array}$} & \multirow[b]{2}{*}{$\mathrm{T}$} & \multirow[b]{2}{*}{ Sig. } \\
\hline & & $\mathrm{B}$ & Std. Error & & & \\
\hline \multirow[t]{3}{*}{1} & (Constant) & .159 & .043 & & 3.735 & .001 \\
\hline & DAR & -.638 & .198 & -1.264 & -3.217 & .003 \\
\hline & DER & .249 & .059 & 1.661 & 4.227 & .000 \\
\hline
\end{tabular}

a. Dependent Variable: ROE

Sumber: Output IBM SPSS 25

Hasil dari analisis regresi liniear berganda menghasilkan persamaan yaitu:

$$
\mathrm{ROE}=0,159-0,638 \mathrm{DAR}+0,249 \mathrm{DER}
$$

Persamaan diatas regresi liniear dapat dijabarkan:

a. Konstanta (a) pada persamaan regresi diataas sebesar 0,159 menunjukkan nilai positif yang artinya variabel DAR dan DER bernilai 0 maka nilai variabel ROE bernilai 0,159

b. Model persamaan regresi diatas yaitu DAR memiliki nilai sebesar -0,638 yang artinya nilai ROE mengalami penurunan 0,638.

c. Model persamaan regresi diatas yaitu DER mrmiliki nilai sebesar 0,249 yang artinya nilai ROE mengalami kenaikan 0,249. 


\section{Pengujian Hipotesis (Uji t)}

Berdasarkan hasil yang diperoleh menggunakan alat bantu SPSS dapat dijabarkan:

1. Variabel DAR

Dapat diketahui dari hasil analisis thitung DAR lebih kecil dari t tabel yaitu 3,217 <2,02439 dengan tingkst signifikansi sebesar 0,003 $<0,05$ sehingga disimpulkan bahwa variabel DAR berpengaruh tidak signifikan terhadap ROE.

2. Variabel DER

Dapat diketahui dari hasil analisis t hitung DER lebih besar dari t tabel yaitu 4,227 > 2,02439 dengan tingkat signifikansi sebesar $0,000<0,05$ sehingga disimpulkan bahwa variabel DER berpengaruh signifikan terhadap ROE.

\section{Pembahasan}

\section{Pengaruh DAR Terhadap ROE}

Nilai DAR merupakan total debet yang dibandingkan dengan total asset. Pada hasil penelitian ini menunjukkan Debt to Asset Ratio (DAR) secara parsial tidak berpengaruh terhadap Return on Equity (ROE). Dari hasil analisis regresi dapat diketahui bahwa DAR memiliki nilai negatif dan tidak signifikansi terhadap ROE, memiliki arti bahwa variabel tersebut DAR tidak dapat mempengaruhi ROE secara signifikan. Rasio yang mampu meningkatkan ROE tidak secara maksimal, hal ini dikarenakan penggunaan modal asing (utang) akan mengurangi profitabilitas perusahaan karena modal asing memberikan pengaruh lebih besar dibandingkan modal sendiri.

\section{Pengaruh DER Terhadap ROE}

Berdasarkan hasil analisis regresi bahwa DER memiliki nilai positif dan mengalami signifikansi terhdap ROE. Dari hasil analisis regresi dapat diketahui DER memiliki nilai positif dan mengalami signifikansi terhadap ROE, memiliki arti bahwa variabel tersebut DER mempengaruhi ROE secara signifikan. Adapun hasil penelitian oleh Jihan Salim (2015) yang mendukung bahwa DER secara parsial memiliki pengaruh positif terhdap ROE.

\section{Pengaruh DAR dan DER Terhadap ROE}

Dari hasil penelitian diketahui variabel DAR dan DER berpengaruh secara signifikan terhadap ROE. Dari hasil perhitungan statistik diketahui nilai signifikansi $0,000<0,05$ (tingkat signifikansi). Sedangkan F tabel bernilai 3,24. Karena F hitung lebih besar dari F tabel yaitu 11,761 > 3,24. Berdasarkan hipotesis dapat dikatakan bahwa variabel terikat yaitu ROE dapat dipenagruhi dipengaruhi secara signifikan oleh variabel bebas yaitu DAR dan DER pada perusahaan properti dan real estate tahun 2013-2017.

\section{Penutup}

\subsection{Kesimpulan}

Berdasarkan hasil penelitian dan pembahasan, maka dapat diambil kesimpulan bahwa pengaruh Debt To Asset Ratio (DAR) dan Debt To Equity Ratio (DER) terhadap Return On Equity (ROE), maka dapat diambil kesimpulan sebagai berikut

1. Variabel Debt to Asset Ratio (DAR) secara parsial memiliki pengaruh tidak signifikan negatif terhadap Return on Equity (ROE) pada perusahaan porperti dan real estate tahun 2013-2017, artinya penggunaan modal asing (utang) akan mengurangi nilai profitabilitas perusahaan karena modal asing memberikan pengaruh lebih besar dibandingkan modal sendiri.

2. Variabel Debt to Equity Ratio (DER) secara parsial memiliki pengaruh terhadap Return on Equity (ROE) pada perusahaan properti dan real estate pada perusahaan properti dan real estate tahun 2013-2017. 
3. Variabel Debt to Asset Ratio (DAR) dan Debt to Equity Ratio (DER) berpengaruh secara signifikan terhadap ROE sebesar 38,9\% dan selisihnya 61,1\% dipengaruhi variabel yang tidak diteliti.

\subsection{Saran}

Berdasarkan hasil yang telah diperoleh peniliti berharap dapat memiliki manfaat untuk pihakpihak yang memiliki kepentingan sebagai penunjang. Adapun saran yang akan diberikan:

1. Hasil peneliti untuk perusahaan yaitu rata-rata ROE yang diambil dari perusahaan cukup kecil nilainya sedangkan utangnya cukup tinggi. Maka dari itu perusahaan perlu lebih berhati-hati dalam mengambil keputusan dalam hal sumber pendaan.

2. Bagi peneliti selanjutnya yang akan melakukan penelitian dengan topic yang sejenis, sebaiknya menambah sampel baik perusahaan maupun variabel lebih besar agar lebih baik sebagai hal perbandingan.

\section{Daftar Pustaka}

Badan Pusat Statistika. (2020). Persentase Rumah Tangga Menurut Provinsi dan Status Kepemilikan Rumah Kontrak/Sewa 1999-2019 (Diakses 23 Juni 2020). Tersedia pada: ttps://www.bps.go.id/statictable/2009/03/12/1541/persentase-rumah-tangga-menurutprovinsi-dan-status-kepemilikan-rumah-kontrak-sewa-1999-2019.html

Indrawan, Rully., dan Poppy Yaniawati (2016). Metode Penelitian. Bandung: PT Refika Aditama.

Kasmir. 2014. Analisis Laporan Keuangan. Edisi Satu. Cetakan Ketujuh. Jakarta : PT Raja Grafindo Persada.

Mai, M. U., \& Setiawan, S. (2020). Pengaruh Struktur Modal Terhadap Kinerja Perusahaan Pada Industri Manufaktur Kriteria Syariah Di Bursa Efek Indonesia. Jurnal Riset Akuntansi dan Keuangan, 8(1), 159-170.

Prakarsa, R. A., \& Setiawan, S. (2018, October). Pengaruh Profitabilitas, Leverage, Dan Ukuran Perusahaan Terhadap Praktik Perataan Laba (Studi Pada Perusahaan Keuangan Sub Sektor Perbankan Yang Terdaftar Di Bursa Efek Indonesia Periode 2015-2017). In Prosiding Industrial Research Workshop and National Seminar (Vol. 9, pp. 719-727).

Saham OK. 2019. Sub Sektor Properti dan Real Estate BEI (diakses 20 Mei 2020). Tersedia pada: https://www.sahamok.com/emiten/sektor-property-real-estate/sub-sektor-propertyrealestate/

Salim, Jihan. 2015. Pengaruh Leverage (DAR, DER, dan TIER) terhadap ROE Perusabaan Properti dan Real Estate yang Terdaftar di Bursa Efek Indonesia 2010-2014. Jurnal Fakultas Ekonomi dan Bisnis Perbanas Institute

Santoso, Budi.2005. Prospek Kredit Properti 2005. Jurnal

Sartono, Agus. (2012). Manajemen Keuangan Teori dan Aplikasi Edisi4. Yogyakarta: BPFEYOGYAKARTA. 